80

\title{
Lessons from a decade of policies for stimulating computer use in the Netherlands
}

\author{
Alfons C. A. ten Brummelhuis \\ University of Twente \\ Enschede \\ The Netherlands
}

\begin{abstract}
In the early 1980's the Dutch government started a policy stimulating the introduction of computers in education which ended in 1992. Currently the Dutch government considers new technologies to be part of regular educational practice not needing further national stimulation. This paper summarizes the results of a decade of stimulation policies in the Netherlands. Hardware and software availability and degree of computer use will be presented for primary education, lower secondary education and vocational educational and will related to policy measures taken on national level. The central theme of the paper is what can be learned from the past for future innovation activities.
\end{abstract}

Main conference themes: national policies

Educational areas: primary education, secondary education, vocational education

Study topics:

Secondary keywords: innovation, policy, research 


\section{INTRODUCTION}

The first section of this paper includes a brief description of the government policy on New Information Technologies in the Netherlands. A distinction is made between three educational levels: primary education, lower secondary education and vocational education.

In the second part for each of these educational levels an overview of the current situation with respect to information technology will be given. This overview is based on findings from several national surveys which were carried out in 1989, 1992 and 1994. The final section summarizes identified bottlenecks in further implementation of computers in education.

\section{Dutch policy on New Information Technologies}

\section{Vocational education}

Since the early 1980's the Dutch government has been pursuing a policy aimed at stimulating the use of computers in education through the Informatics Stimulation Plan (INSP). For vocational education the major objective of the plan was to improve the quality of vocational preparation of 'human capital' [1]. For this purpose vocational schools were supported with hardware, software and training. As the initial results of this stimulation policy in vocational education were disappointing, a new project called PRESTO (Project management for effective promotion of technology in vocational education) started in 1991. A major difference with the previous stimulation policy is that PRESTO was concentrating on development of teaching materials within the school context. Vocational schools had to elaborate their ideas with regard to technical innovation and write a so-called Technical Innovation Program (TIP). This is a kind of project proposal indicating what technological innovations are current practice in businesses for which pupils are educated, how the school is aiming to distinguish themselves in a technological sense, what actual projects have priority on the short term and how these are going to be implemented and funded. PRESTO leaves the initiative in the hands of the vocational educational institutions and provides only support for joint financing of projects.

\section{Lower secondary education}

For the first phase of secondary education the INSP-plan (1984-1988) primarily focused on the introduction of computer education as a subject (Information and Computer Literacy: ICL). A second aim was the application of new technologies for the improvement of the teaching-learning process itself. To support the implementation process several measures were taken during the INSP-period, the most important one being the NIVO-project (New Information Technology in Secondary Education). This project aimed to 
provide hardware and software to all schools in secondary education, development of courseware and training for three teachers per school. National policy initiated within the framework of the INSP was continued within the framework of the OPSTAP (Operational Plan STimulation Activities and Procedures) in the period 1989-1992 [2]. The policy for the first phase of secondary education during this period focused on further integration of computer education in the curriculum and the integration of information technology elements in existing subjects. After a period of dissemination of hardware and the stimulation of computer use during the INSP-years the most important goal in the OPSTAP-period was the broadening of computer use in secondary education. This meant a focus on the application of the computer in existing subjects. In 1992 it became clear that additional stimulation activities were necessary to realize this goal. For that purpose a small project started in 1993: PIT (Project on Information Technology). In total 125 schools (8\% of all lower secondary schools) participate in this project towards the goal of using the computer actively in various school subjects. These 125 schools are financially supported for two years.

\section{Primary education}

During the INSP-period the government paid only limited attention to the stimulation of computer use in primary education. In a few projects the possibilities of computers in this educational sector were examined. Since 1989 there is also broad national support for primary education. This policy is carried out in the so-called PRINT/Comenius project with an integrated focus on hardware, software, training and support. Each elementary school received hardware in a ratio of one computer per 60 pupils. Furthermore each school received a starting package of software, a printer and a credit for the acquisition of additional software. To qualify for the provision of hardware and software, the personnel of the school had to follow a training and the targeted computer use had to be laid down in a school policy document.

\section{The current situation}

\section{Vocational education}

Since 1991 most of the 200 institutions for vocational education have developed a school bound Technological Innovation Program. In spring 1993 more than 600 innovation project plans were accepted by the PRESTO management for financial support. Total project costs were 50 million Dutch guilders. By the end of 1993, when the support of the PRESTO project stopped, more than $50 \%$ of the Technological Innovation projects were not finished. At $30 \%$ of the vocational education institutions none of the innovative projects were completed. As far as TIP's were finished, by the end of the project the school 
project coordinator stated that $90 \%$ of the developed lesson materials were useful for educational purposes [3]. Until now there are no data available about the use of the developed lesson materials and the impact on the vocational training of students.

\section{Lower secondary education}

Since 1990 all schools for lower secondary education are in the possession of computers, partly because of the provision of hardware by the government, but also because many schools have themselves bought computers. In 1992 there were on average 24 computers per school most of which were equipped with the MS-DOS operating system. In 1989 computer education was taught in the first three years of secondary education in $88 \%$ of the schools. In 1992 this percentage rose to $94 \%$ - only in $6 \%$ of the secondary schools computer education was not yet included in the timetable of one of the first three years. In a number of schools computer education was also included in the timetable of one of the higher grades.

The most recent development in Dutch education is the New Basic Education which started in August 1993. This is a basic comprehensive curriculum for all pupils between the age of 12 and 15, embracing the first three years of secondary education. As part of the curriculum for New Basic Education a 20 hours course on 'Information and computer literacy' (ICL) is compulsory for all students. Furthermore computer use as tool and/or aid in other subject areas is stimulated. Focused curriculum development activities have been started to stimulate this process.

Computers are mainly used in computer education (ICL) classes. Within the second grade of secondary education the integration of the computer in existing subjects is limited (Mathematics 12\%, Science 6\% and Dutch language 7\%) as was found in 1989.

As has been mentioned in the previous paragraph the government policy during the OPSTAP period (1989-1992) has been aimed at broadening computer use within existing subjects. Although computer use has at least doubled in this period, in each of the studied existing subjects only $1-2 \%$ of the teachers use the computer frequently. The increase of computer use in existing subjects since 1989 can almost entirely be attributed to teachers who work within a department in which no other teacher had yet made use of the computer in the second grade. The policy aim of broadening computer use within existing subjects has hence been achieved among schools, but not within the various departments of a school - especially not within schools which in 1989 already made use of the computer in existing subjects [4]. Computer use in existing subjects of the first phase of secondary education is therefore an activity of the individual teacher and is not embedded in the curriculum. 


\section{Primary education}

In spite of the absence of broad stimulation by the government during the INSP period in 1989 a little more than half of the elementary schools already possessed computers. On average these schools had three computers. Most schools financed these computers from their own funds or participated in a local or regional introduction projects. The most frequently used type of computers in 1989 were P2000/MSX computers (58\%) and C64/AppleII $(22 \%)$. In 1992 more than $50 \%$ of all available computers were MS-DOS machines and in the period of 1990-1994 the number of elementary schools with computer hardware increased from $51 \%$ to $98 \%$.

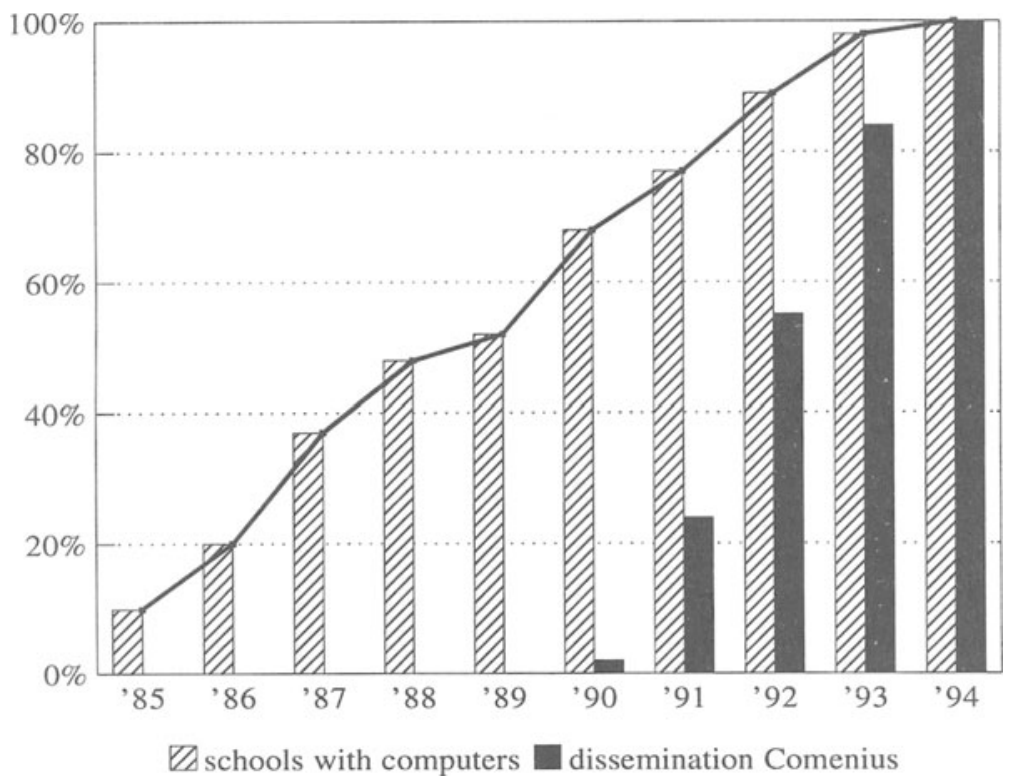

Fig. 1 Overview of the acquisition of computer hardware by elementary schools

The influence of the Government supported Comenius project on the dissemination of computer hardware in primary education is depicted in Figure 1. Based on the results of 1989 it became apparent that almost all elementary schools which have computers actually use these for educational purposes. In 1989 on average $75 \%$ of the teachers in grade 4-6 (students in the age range 911) in computer using schools used computers for instruction. In 1994 the percentage of teachers who actually make use of computers is $66 \%$. This is a decrease, but does not entail that computer use has decreased in primary 
education. On the contrary: due to the increase in the number of schools having computers a significant growth took place in the number of teachers who make use of the computer in primary education [4].

In 1994 all primary schools possessed a word processing program; most of these also have (educational) games programs and drill and practice software. Most schools have programs for arithmetic, Dutch language and geography. For all subjects drill and practice is the most common computer application. No essential changes in school organization took place due to computer use in the sense of any shift from traditional to individualized teaching nor is any completely new interpretation of the role of the teacher found [5].

\section{Bottlenecks and lessons from the past}

The national policies for stimulating the introduction of computers in vocational, secondary and primary education coincide on the points: availability of hardware, software and training. The policies took the most important hindrances to the use of computers in the classroom into consideration which were indicated in 1989 by teachers, computer coordinators and directors of schools: too few computers, insufficient usable software and lack of knowledge. A fourth bottleneck mentioned in all educational sectors is insufficient time for introduction. No policy measures were taken to overcome the shortage of time teachers experienced during their training and the implementation of the computer within the classroom.

In general the effectiveness of implementation stimulating measures is determined by the degree of internal coherence of the measures. In this case the lack of taking the fourth bottleneck into account, for example by supplying nonteaching hours which enable teachers to prepare, could negatively influence the effectiveness of other implementation stimulating measures. Especially when using computers as a tool many teachers first want to learn more about the possibilities of the computer before substituting the security of their teaching routine by the insecurities which accompany the introduction of the computer in the classroom. In 1989 and 1992 more than $60 \%$ of teachers in lower secondary schools which did not use computers, indicated that the educational added value of the computer was not clear to them. It seems to be important that good examples of practical programs become available which illustrate the value of computer use in existing subjects [6].

Lessons to be learned from the Dutch stimulation policies are:

- the conditions for the introduction of computer use as a separate subject are not sufficient to realize the integration of computers in existing subjects as well; 
- courseware development for computer use in existing subjects needs to be tuned to the curriculum;

- the didactic and organizational aspects of using the computer in daily educational practice need to be part of teacher training;

- at school level provisions for whole class computer use need to be made, such as one computer per classroom or computers on wheels;

- internal coherence of stimulation activities is a precondition to prevent computer use from being a hobby of an individual teacher and to allow this to get embedded in the curriculum of existing subjects.

\section{REFERENCES}

1. Ministry of Education (1985) Het informatica stimuleringsplan en de rol van $O \& W$ (The Information Technology Stimulation Plan and the role of the Ministry for Education) PSOI-reeks 1. Zoetermeer: SDU.

2. Ministry of Education (1988) Policy Document for the OPSTAP operation: to information technology in Education in the Netherlands. PSOI-reeks 36. Zoetermeer: SDU.

3. Brummelhuis, A.C.A. ten (1994) Tweede voortgangsmeting van technologische innovatie programma's in het middelbaar en cursorisch beroepsonderwijs (Second progress report about Technological Innovation Projects in vocational education). Enschede: University of Twente.

4. Brummelhuis, A.C.A. ten and Plomp, Tj. (1994) Computer in primary and secondary education: The interest of an individual teacher or a school policy. Computers and Education 22 (4) pp. 291-299.

5. Zoelen, L. van., Brummelhuis, A.C.A. ten., Janssen Reinen, I.A.M. and Poorthuis, T. (1994) Computergebruik en behoeften aan ondersteuning in het primair onderwijs (Computer use and the need for support in elementary education). Utrecht: University of Utrecht.

6. Brummelhuis, A.C.A. ten and Plomp, Tj. (1993) Lessons from two Dutch projects for the introduction of computers in schools. Computers and Education 20 (4) pp. 333-340. 